\title{
Effectiveness of statins for secondary prevention in elderly patients after acute myocardial infarction: an evaluation of class effect
}

\author{
Zheng Zhou, Elham Rahme, Michal Abrahamowicz, Jack V. Tu, Mark J. Eisenberg, \\ Karin Humphries, Peter C. Austin, Louise Pilote
}

ß See related article page 1195

Abstract

Background: Clinical trials have shown the benefits of statins after acute myocardial infarction (AMI). However, it is unclear whether different statins exert a similar effect in reducing the incidence of recurrent AMI and death when used in clinical practice.

Methods: We conducted a retrospective cohort study (1997-2002) to compare 5 statins using data from medical administrative databases in 3 provinces (Quebec, Ontario and British Columbia). We included patients aged 65 years and over who were discharged alive after their first AMI-related hospital stay and who began statin treatment within 90 days after discharge. The primary end point was the combined outcome of recurrent AMI or death from any cause. The secondary end point was death from any cause. Adjusted hazard ratios (HRs) for each statin compared with atorvastatin as the reference drug were estimated using Cox proportional hazards regression analysis.

Results: A total of 18637 patients were prescribed atorvastatin ( $\mathrm{n}=$ 6420), pravastatin ( $n=4480)$, simvastatin $(n=5518)$, lovastatin ( $n=1736)$ or fluvastatin $(n=483)$. Users of different statins showed similar baseline characteristics and patterns of statin use. The adjusted HRs (and 95\% confidence intervals) for the combined outcome of AMI or death showed that each statin had similar effects when compared with atorvastatin: pravastatin 1.00 (0.90-1.11), simvastatin $1.01(0.91-1.12)$, lovastatin 1.09 (0.95-1.24) and fluvastatin 1.01 (0.80-1.27). The results did not change when death alone was the end point, nor did they change after adjustment for initial daily dose or after censoring of patients who switched or stopped the initial statin treatment.

Interpretation: Our results suggest that, under current usage, statins are equally effective for secocondary prevention in elderly patients after AMI.

CMAJ 2005;172(9):1187-94 andomized controlled trials (RCTs) have shown that the use of statins after acute myocardial infarction (AMI) are effective in reducing the incidence of both fatal and nonfatal cardiovascular events..$^{1-8}$ Although these trials have significantly influenced post-AMI treatment, ${ }^{9-12}$ it remains unclear whether all statins are equally effective in preventing recurrent AMI and death. Drugs in the same class are generally thought to be therapeutically equivalent because of similar mechanisms of action (class effect). ${ }^{13-15}$ However, in the absence of comparative data, this assumption requires evaluation. Statins differ in multiple characteristics, including liver and renal metabolism, half-life, effect on other serum lipid components, bioavailability and potency. ${ }^{16-19}$ These differences could potentially influence the extent to which the drugs are beneficial. Despite limited evidence in support of a differential benefit of statins for secondary prevention, preferential prescribing already occurs in practice and cannot be fully explained by the existing evidence or guidelines..$^{20}$ Comparative data of statins are thus required to inform health care decision-making.

A number of RCTs have directly compared statins using surrogate end points, such as lipid reduction, ${ }^{21-23}$ markers of hemostasis and inflammation ${ }^{24-26}$ or reduction in number of atherotic plaques. ${ }^{27}$ However, the extent to which these results can be extrapolated to clinically relevant outcomes remains to be established. The newly released PROVE ITTIMI 22 triall $^{28}$ was the first trial to compare 2 statins for cardiovascular prevention. The study showed that atorvastatin used at a maximal dose of $80 \mathrm{mg}$ (intensive therapy) was better than pravastatin at a dose of $40 \mathrm{mg}$ (standard therapy) in decreasing the incidence of cardiovascular events and procedures. The study was, however, conducted to show the benefit associated with increased treatment intensity. It did not compare the drugs by milligramequivalent doses or by cholesterol-lowering equivalent doses. Moreover, no difference was detected when death alone or the combined outcome of death or AMI was evaluated. Other than the PROVE IT-TIMI 22 trial, few data are currently available from RCTs that compare statins for cardiovascular prevention. ${ }^{29}$

We conducted a population-based study to examine the relative effectiveness of different statins for long-term secondary prevention after AMI. We used retrospective cohorts of elderly patients prescribed statins after AMI in 3 provinces. Five statins were studied: atorvastatin, pravastatin, simvastatin, lovastatin and fluvastatin. The newest statin, rosuvastatin, was not available during the study period and was not considered in this study. 


\section{Methods}

Three comparable AMI cohorts were created by using the linked hospital discharge databases and the physician and prescription claims databases in Quebec, Ontario and British Columbia. We used standardized inclusion and exclusion criteria as well as comorbidity information across provinces according to concurrent collaborations at the national level in cardiovascular outcome research. ${ }^{30,31}$ Several validation studies have ensured the accuracy of coding in each province. . $^{30,32,33}$

Information regarding outpatient prescriptions and therapeutic procedures was obtained from the physician and prescription claims databases (the Ontario Drug Benefits database, the BC PharmaCare Program and the Régie de l'assurance maladie du Québec [RAMQ]). All patients aged 65 years and over receive free prescription coverage in Canada. Available prescription information included type, dosage, quantity and days of supply. Death information was obtained from provincial registry databases (Ontario Registered Persons, BC Vital Statistics and RAMQ). All data were linked by the patients' unique, encrypted health care insurance number.

Patients were included if they were 65 years or older, had their first recorded AMI-related hospital admission and were discharged alive between 1997 and 2001, and had their statin prescription filled within 90 days after discharge. All patients had AMI (ICD-9-CM ${ }^{34}$ code 410) recorded as the most responsible diagnosis in the hospital discharge database (Canadian Institute for Health Information for Ontario and BC data, and Med-Echo [Maintenance et exploitation des données pour l'étude de la clientèle hospitalière] for Quebec data).

We excluded patients if they met any of the following criteria: the AMI was coded as an in-hospital complication; the AMIrelated hospital admission was a transfer from another hospital (to avoid counting patients twice, yet all transfers related to the initial AMI admission were counted in the total length of hospital stay); the total length of hospital stay was less than 3 days (to exclude ruled-out AMI cases and those admitted only for procedures); the patient was discharged to a long-term care institution or a rehabilitation centre or moved out of the province; or the health care number was invalid. More details of the rationale for these criteria can be found elsewhere. ${ }^{30,35}$

Cohort enrolment began on Apr. 1, 1997, and ended on Mar. 31, 2001 (1 year before the end of the study to ensure a potential for at least 1-year follow-up for every patient). Follow-up for each patient was from the time of the first statin prescription (time 0 ) to the occurrence of a study end point or the end of the study period. On the basis of the first statin prescribed, 5 statin groups were formed (atorvastatin, pravastatin, simvastatin, lovastatin and fluvastatin). For statin usage patterns, we recorded the number of patients who switched or stopped the initially prescribed statin treatment. Stopping treatment was defined as discontinuation of the initial statin or the absence of a prescription for the initial statin 15 or more days after the end of the previous prescription. To indicate patient persistence on the treatment, we calculated the ratio of the total number of days supplied for the initial statin divided by the total number of follow-up days.

Patient demographic characteristics and comorbidities at discharge were determined from the hospital discharge databases. Comorbidities included coexisting cardiovascular and lung diseases, chronic kidney or liver conditions as well as diabetes mellitus, dementia and malignant disease. Concurrent use of major cardiac medications was also recorded. These drugs included $\beta$ - blockers, angiotensin-converting-enzyme inhibitors, antiplatelet drugs (ASA, clopidogrel), calcium-channel blockers, diuretics, warfarin and digoxin. Use of statins during the year before the index AMI was included as a baseline covariate. Information was obtained regarding the in-hospital procedure performed (catheterization, percutaneous coronary intervention or coronary artery bypass graft surgery), length of hospital stay, time to first statin prescription, year of AMI, specialty of the treating physician (cardiologist, internist, general practitioner or other specialist), type of hospital (teaching or not), hospital volume, hospital location (urban or rural) and availability of cardiac catheterization facility in the hospital.

The primary end point was defined as a combined outcome of recurrent $\mathrm{AMI}$ or death from any cause, whichever occurred earlier. The secondary outcome was death from any cause.

Descriptive statistics were used to compare baseline patient characteristics between statin groups. A multivariate Cox proportional hazards model was used to assess the associations between type of statin used and time to study outcome. The proportional hazard assumption was assessed by a plot of $\log (-\log$ (survival function)) versus time for both primary and secondary outcomes. The linearity assumption was assessed for continuous variables in the model, including age, length of hospital stay and time to first statin prescription. These variables were categorized if the linearity assumption was not met.

Analyses were performed in 2 ways. First, in an intention-totreat analysis, patients were assumed to be taking the initial statin throughout follow-up. In a second analysis, patients were censored at the time of switching or stopping the initial statin. Adjusted hazard ratios (HRs) for each statin compared with the reference statin (atorvastatin) and 95\% confidence intervals (CIs) were reported, with adjustment made for baseline characteristics and potential confounders. To examine the robustness of our results, we did several additional analyses. First, to assess the impact of statin dose, we adjusted for the initial daily dose of each statin by creating a binary variable "at or above target dose." We determined the target dose by referring to the cholesterollowering equivalent $\operatorname{dose}^{21,36}$ as well as the dose tested in the largescale RCTs of each statin for long-term cardiovascular prevention. ${ }^{1,2,5,8,37-40}$ The target dose was set as $10 \mathrm{mg}$ for atorvastatin and $40 \mathrm{mg}$ for the other statins. The binary variable "at or above target dose" was subsequently adjusted in the Cox model. Second, results were stratified according to statin use (yes or no) before the index AMI to examine whether the effect depended on the history of statin use. Finally, to ensure that the results did not depend on the choice of the reference statin, a likelihood ratio test with 4 degrees of freedom (df) was performed with the hypothesis that all of the statins had the same effects.

We applied the same methods to the data from each of the 3 provinces. We then pooled the HRs for each statin (compared with atorvastatin) using a fixed-effects model, with weight being the inverse of the variance of the province-specific parameter estimate. ${ }^{41}$ A test of heterogeneity was performed to examine the appropriateness of using a fixed-effects model to pool the estimates. ${ }^{42}$

\section{Results}

Of the 56408 identified AMI patients, 18637 (33.0\%) had filled a prescription within 90 days after discharge for atorvastatin $(n=6420)$, pravastatin $(n=4480)$, simvastatin $(n=5518)$, lovastatin $(n=1736)$ or fluvastatin $(n=483)$. 
The median follow-up was 2.3 (range 1-5, interquartile range 1.6-3.2) years.

A comparison of baseline demographic and clinical characteristics did not reveal any major differences across the statin groups (Table 1). Notable exceptions were that (a) lovastatin users tended to have more comorbidities and possibly a longer cardiac history, as suggested by greater use of diuretics and calcium-channel blockers and higher prevalence of congestive heart failure; and (b) fluvastatin was found to be prescribed more by general practitioners and less by cardiologists, and fluvastatin users were more often treated in rural hospitals and less often underwent revascularization procedures during the initial hospital stay. Nevertheless, a pattern of preferential prescribing of a particular statin to sicker or healthier patients did not emerge.

Table 1: Characteristics of elderly patients prescribed statins after acute myocardial infarction (AMI) in Quebec, Ontario and British Columbia

\begin{tabular}{|c|c|c|c|c|c|}
\hline \multirow[b]{2}{*}{ Characteristic } & \multicolumn{5}{|c|}{ Statin; weighted value* } \\
\hline & $\begin{array}{c}\text { Atorvastatin } \\
n=6420\end{array}$ & $\begin{array}{c}\text { Pravastatin } \\
n=4480\end{array}$ & $\begin{array}{l}\text { Simvastatin } \\
n=5518\end{array}$ & $\begin{array}{l}\text { Lovastatin } \\
n=1736\end{array}$ & $\begin{array}{c}\text { Fluvastatin } \\
n=483\end{array}$ \\
\hline \multicolumn{6}{|l|}{ Patient } \\
\hline Age, median, $\dagger$ yr & $72(72,72)$ & $72(71,73)$ & $73(71,73)$ & $73(72,73)$ & $72(72,73)$ \\
\hline Sex, \% male & $59(59,62)$ & $61(59,63)$ & $61(60,64)$ & $56(50,61)$ & $57(56,59)$ \\
\hline \multicolumn{6}{|l|}{ Comorbidity at baseline, $\%$} \\
\hline Hypertension & $32(27,39)$ & $31(24,37)$ & $31(29,36)$ & $32(28,41)$ & $29(26,31)$ \\
\hline Diabetes mellitus & $25(20,27)$ & $23(19,25)$ & $23(17,24)$ & $24(20,26)$ & $25(20,29)$ \\
\hline Congestive heart failure & $20(15,21)$ & $19(13,20)$ & $20(14,22)$ & $23(17,28)$ & $18(16,22)$ \\
\hline Cardiac dysrhythmia & $15(12,18)$ & $15(12,17)$ & $15(12,18)$ & $15(13,19)$ & $13(11,16)$ \\
\hline COPD & $10(6,16)$ & $11(9,17)$ & $10(9,16)$ & $11(9,16)$ & $11(6,19)$ \\
\hline Cerebrovascular disease & $4 \quad(1,7)$ & $5 \quad(2,8)$ & $4 \quad(2,8)$ & $5 \quad(2,8)$ & $5 \quad(2,6)$ \\
\hline Chronic renal failure & $4(1,7)$ & $5 \quad(1,7)$ & $4(1,7)$ & $4(1,9)$ & $4 \quad(1,9)$ \\
\hline Malignant disease & $2(1,2)$ & $2(1,2)$ & $2(1,3)$ & $2(1,2)$ & $2(1,3)$ \\
\hline Dementia & $1(1,1)$ & $1(0,1)$ & $1(0,1)$ & $1(1,1)$ & $1(0,2)$ \\
\hline \multicolumn{6}{|l|}{ In-hospital procedure } \\
\hline Catheterization & $30(24,47)$ & $29(21,45)$ & $28(22,42)$ & $29(17,43)$ & $26(23,33)$ \\
\hline $\mathrm{PCl}$ & $12(8,25)$ & $12(7,22)$ & $11(6,22)$ & $12(6,23)$ & $9 \quad(5,19)$ \\
\hline CABG & $4(2,11)$ & $3(1,6)$ & $4(2,8)$ & $5 \quad(2,12)$ & $5 \quad(4,6)$ \\
\hline Length of hospital stay, median, $\uparrow d$ & $7 \quad(7,9)$ & $8(7,9)$ & $8(7,9)$ & $8(7,10)$ & $8(7,9)$ \\
\hline \multicolumn{6}{|l|}{$\begin{array}{l}\text { Cardiac medication (before first statin } \\
\text { prescription) }\end{array}$} \\
\hline Nitrate & $71(62,73)$ & $71(66,74)$ & $72(68,74)$ & $69(61,74)$ & $67(66,70)$ \\
\hline$\beta$-Blocker & $71(65,73)$ & $67(65,67)$ & $67(62,69)$ & $63(61,64)$ & $64(55,69)$ \\
\hline ACE inhibitor & $56(45,60)$ & $52(47,55)$ & $53(45,57)$ & $49(42,51)$ & $48(42,51)$ \\
\hline Antiplatelet agent $\ddagger$ & $54(51,64)$ & $57(54,63)$ & $54(51,61)$ & $50(47,59)$ & $55(54,57)$ \\
\hline Diuretic & $28(22,28)$ & $28(23,29)$ & $28(23,29)$ & $33(27,35)$ & $26(23,28)$ \\
\hline Calcium-channel blocker & $24(22,25)$ & $24(19,24)$ & $25(19,26)$ & $30(18,35)$ & $24(22,26)$ \\
\hline Warfarin & $12(7,16)$ & $13(12,13)$ & $13(9,13)$ & $14(11,15)$ & $14(7,20)$ \\
\hline Digoxin & $11(9,16)$ & $12(8,14)$ & $11(10,13)$ & $14(12,17)$ & $10(6,12)$ \\
\hline \multicolumn{6}{|l|}{ Physician } \\
\hline Cardiologist & $39(36,48)$ & $42(37,50)$ & $40(35,48)$ & $38(34,45)$ & $27(20,32)$ \\
\hline Internist§ & $35(10,41)$ & $30 \quad(9,40)$ & $36(14,43)$ & $31(10,38)$ & $35(20,44)$ \\
\hline GP or other & $26(22,41)$ & $28(23,40)$ & $24(19,37)$ & $31(21,44)$ & $38(26,41)$ \\
\hline \multicolumn{6}{|l|}{ Hospital } \\
\hline Teaching hospital & $21 \quad(5,23)$ & $17 \quad(5,20)$ & $23 \quad(7,25)$ & $21(8,27)$ & $11(4,18)$ \\
\hline Catheterization facility available & $18(14,31)$ & $23(16,37)$ & $21(18,27)$ & $25(22,34)$ & $12(10,19)$ \\
\hline Rural location $₫$ & $4 \quad(4,6)$ & $5 \quad(4,8)$ & $4(3,6)$ & $5 \quad(5,6)$ & $11(7,15)$ \\
\hline \multicolumn{6}{|c|}{$\begin{array}{l}\text { Note: } \mathrm{COPD}=\text { chronic obstructive pulmonary disease, } \mathrm{PCl}=\text { percutaneous coronary intervention, } \mathrm{CABG}=\text { coronary artery bypass graft surgery, } \mathrm{ACE}=\text { angiotensin- } \\
\text { converting enzyme, } \mathrm{GP}=\text { general practitioner. } \\
\text { *Weighted proportion of patients, unless specified otherwise; numbers in parentheses represent the lowest and highest values for the } 3 \text { provinces. } \\
\text { tWeighted median; figures in parentheses represent the lowest and highest values for the } 3 \text { provinces. } \\
\text { flncludes ASA and clopidogrel. } \\
\text { \$Excludes cardiologist. } \\
\text { ๆ Defined as having } 0 \text { in the middle of the first } 3 \text { digits of the postal code (as per Canada Post definition). }\end{array}$} \\
\hline
\end{tabular}


Use of any statin within 1 year before the index AMI was similar for atorvastatin, pravastatin and simvastatin users but was more frequent among lovastatin and fluvastatin users (Table 2). No apparent delay in filling a first prescription was associated with any particular statin. The median duration of use of the initial statin during the first year of follow-up was similar across the statin groups (330-365 days) except for fluvastatin (307 days). This difference could be explained by the higher switching rates among fluvastatin users. On average, more than $85 \%$ of the patients in each group had initial statin prescriptions that covered at least $80 \%$ of the follow-up period.

The overall proportion of statin users who switched to a different statin during the first year of follow-up was low (7\%), but increased to $21 \%$ by the end of follow-up. Among patients who switched, $55 \%$ switched to atorvastatin. Fluvastatin and lovastatin users had the highest rates of switching (Table 2). To assess whether switching to atorvastatin was related to a change in disease state, we examined the rates of hospital readmission because of cardiovascular causes and the rates of cardiac medication use from the first prescription to the time of switching and compared them between patients who switched to atorvastatin and those who switched to another statin. No significant difference in these rates was found. The overall proportion of patients who stopped statin treatment during follow-up was $11 \%$, with similar percentages across the statin groups (Table 2).
In terms of the distribution of daily doses, we found that in most cases the statins were prescribed at their lower doses (10-20 mg) (Table 2), which are approximately equivalent in lowering cholesterol levels. ${ }^{21}$ Very few subjects $(0.7 \%)$ were prescribed the highest dose of each statin. For example, among the atorvastatin users, only $0.5 \%$ of them were prescribed an $80-\mathrm{mg}$ dose. The proportion of patients who changed doses was low and was similar in the atorvastatin, pravastatin and simvastatin groups. The doses of fluvastatin and lovastatin changed less frequently (Table 2).

A total of 2924 patients either had an AMI or died. The unadjusted cumulative incidences of each outcome for each statin group are shown in Table 3. Patients in the lovastatin group appeared to be at higher risk of recurrent AMI or death compared with those in the other statin groups, although the difference was not statistically significant.

The results of the multivariate survival analysis are summarized in Table 4. Higher age, male sex and most major comorbidities were associated with increased risk, whereas cardiac procedures and use of some cardiac medications showed protection. Patients using diuretics, calciumchannel blockers and digoxin and patients who were using statins before the index AMI were at increased risk of AMI or death. This effect could be an indication of greater disease severity associated with use of these medications. ${ }^{43}$ Hypertension did not appear to be a significant risk factor.

Table 2: Pattern of statin usage

\begin{tabular}{|c|c|c|c|c|c|}
\hline \multirow[b]{2}{*}{ Variable } & \multicolumn{5}{|c|}{ Statin; weighted \% of patients* } \\
\hline & Atorvastatin & Pravastatin & Simvastatin & Lovastatin & Fluvastatin \\
\hline Use of statin before index AMI† & $33(27,37)$ & $37(32,38)$ & $35(32,40)$ & $53(37,58)$ & $42(37,50)$ \\
\hline \multicolumn{6}{|l|}{ Time to first statin prescription after } \\
\hline \multicolumn{6}{|l|}{ Duration of statin use in the first } \\
\hline Persistence§ & $0.94(0.87,0.99)$ & $0.94(0.87,1.00)$ & $0.94(0.87,0.99)$ & $0.94(0.89,1)$ & $0.95(0.88,1)$ \\
\hline \multicolumn{6}{|l|}{ Switched from initial statin } \\
\hline During first year & $3(3,3)$ & $9(8,9)$ & $6(6,7)$ & $13(12,15)$ & $17(14,23)$ \\
\hline During follow-up & $8 \quad(8,9)$ & $29(24,31)$ & $22(22,26)$ & $41(36,43)$ & $50(42,56)$ \\
\hline Stopped statin treatment during follow-up & $10 \quad(9,12)$ & $10(10,12)$ & $11(10,12)$ & $12(9,13)$ & $13(10,18)$ \\
\hline Daily dose, median, mg & $10(10,10)$ & $20(20,20)$ & $20(20,20)$ & $20(20,20)$ & $20(20,20)$ \\
\hline \multicolumn{6}{|l|}{ Dose distribution } \\
\hline $10 \mathrm{mg}$ & 66 & 12 & 46 & 2 & 0.2 \\
\hline $20 \mathrm{mg}$ & 28 & 71 & 47 & 82 & 75 \\
\hline $40 \mathrm{mg}$ & 5 & 16 & 7 & 15 & 24 \\
\hline $80 \mathrm{mg}$ & 0.5 & 0.6 & 0.4 & 1 & 0.8 \\
\hline \multicolumn{6}{|l|}{ Dose changed during follow-up } \\
\hline Increased & $13(11,14)$ & $13(11,15)$ & $13(11,14)$ & $10(10,11)$ & $11(9,11)$ \\
\hline Decreased & $5 \quad(5,6)$ & $5 \quad(4,6)$ & $6(4,6)$ & $4 \quad(3,4)$ & $3(1,4)$ \\
\hline
\end{tabular}

*Unless specified otherwise; numbers in parentheses represent the lowest and highest values for the 3 provinces.

†Any statin use within 1 year before the index AMI.

$\neq$ Weighted median; numbers in parentheses represent the lowest and highest values for the 3 provinces.

§Defined as the ratio of the total number of days supplied for the initial statin divided by the total number of follow-up days.

T Median daily dose of statin initially prescribed after AMI. Starting and maintenance dose as recommended in the 2002 Compendium of Pharmaceuticals and Specialties: atorvastatin

10-20 mg; pravastatin 20-40 mg; simvastatin 10-40 mg; lovastatin 20-40 mg; fluvastatin 20-40 mg. 
This could be due to the inclusion of anti-hypertensive medications in the risk adjustment model. A delay in initiating statin therapy appeared to be "protective"; however, this effect was due to a decreasing risk over time after discharge, which was independent of statin treatment effect. None of the physician and hospital characteristics was significantly associated with outcome. No apparent secular trend in the event rate was detected.

For all statins, the heterogeneity test of estimates (HRs) from the 3 provinces suggested a homogenous effect (all $p$ values $>0.62,2 \mathrm{df}$ ). The pooled adjusted HRs and $95 \%$ CIs for the combined outcome of recurrent AMI or death showed that each statin had similar effects when compared with atorvastatin (Fig. 1). Adjustment for initial daily dose of each statin according to whether it was "at or above target dose" did not materially change the results. Stratified analyses according to prior statin use did not affect the results, nor did restricting the outcome to death or censoring patients who switched or stopped the initial statin treatment. The likelihood ratio test confirmed the absence of any statistically significant difference in risk between patients prescribed different statins $(p>0.41,4 \mathrm{df})$. Finally, we performed post hoc comparisons of (a) atorvastatin versus the other statins and (b) lovastatin versus the other statins. The latter comparison was done because the lovastatin group showed a slightly increased incidence of clinical end points. The results were unchanged in each comparison: HR for recurrent AMI or death was 0.98 (95\% CI 0.90-1.07) for the comparison of atorvastatin with the other statins and 1.09 (95\% CI 0.98-1.22) for the comparison of lovastatin with the other statins.

\section{Interpretation}

The results of our population-based study of commonly used statins suggest that individual drugs in the statin class exhibit a similar effect in reducing the incidence of recurrent AMI or death among elderly patients.

Individual statins have been shown in several studies to be of benefit in reducing the incidence of recurrent AMI and death among patients who have experienced an AMI. These studies included the $4 \mathrm{~S}$ trial $^{1}$ (simvastatin), the $\mathrm{CARE}^{2}$ and the LIPID trials ${ }^{5}$ (pravastatin), and the GREACE ${ }^{8}$ trial (atorvastatin). The benefit has also been evident in recent trials that enrolled subjects with and without prior cardiovascular diseases but who were at high risk of future cardiovascular events, including the HPS trial ${ }^{38}$ (simvastatin) and the PROSPER trial ${ }^{4+}$ (pravastatin). In each trial, the statin was compared with a placebo. It is not evident whether the effect size observed across trials varied because of different trial characteristics or because the statins had truly different effects. The results of the PROVE IT-TIMI 22 trial suggested that a statin used at a high dose could provide additional benefits, ${ }^{28}$ yet $80 \mathrm{mg}$ of atorvastatin was not frequently prescribed in practice during our study period. Compared with the patients in our study, those in the PROVE IT-TIMI 22 trial were younger (mean age 58 years), mostly male (78\%) and had less comorbidity and thus were more likely to tolerate a high dose of statin and experience the benefit. In our head-to-head comparison of 5 statins, we examined the relative effectiveness of the drugs in older patients with a more diverse risk profile, a populationbased setting that is representative of daily practice.

Our study was a retrospective analysis of administrative databases, and thus several limitations merit discussion. First, because the patients studied were all receiving statin therapy, there is a lower likelihood of confounding by indication. ${ }^{45}$ However, we could not control for all patient characteristics that may influence physicians' choice of statin. Unmeasured comorbidity as well as missing clinical data (e.g., cholesterol levels, location of MI) could confer residual confounding effects; however, there is no obvious reason that prescribing of different statins would be strongly influenced by these unmeasured characteristics. The analysis of available baseline characteristics did not suggest preferential prescribing of a particular statin to sicker patients. In addition, we controlled for the specialty of treating physician and the type of hospital, which could be associated with statin selection and intensity of therapy.

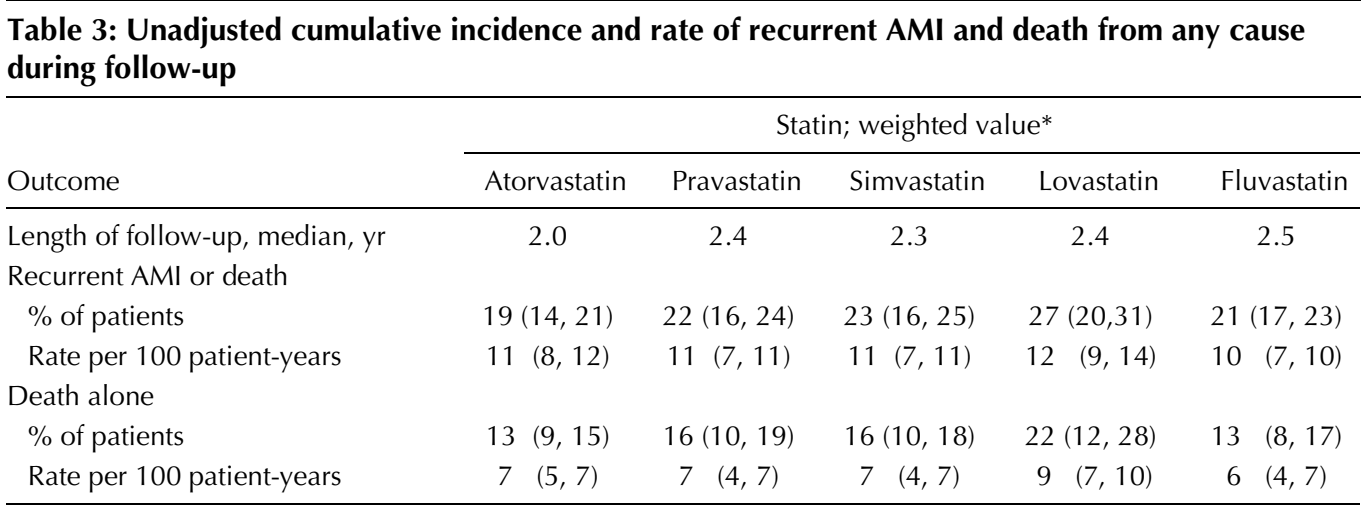

*Weighted percentage of patients or weighted rate, unless specified otherwise; numbers in parentheses represent the lowest and highest values for the 3 provinces. 


\section{Table 4: Factors associated with recurrent AMI and death from any cause among elderly patients}

\begin{tabular}{|c|c|}
\hline Factor & $\begin{array}{l}\text { Adjusted hazard ratio } \\
\text { (and } 95 \% \mathrm{Cl})^{*}\end{array}$ \\
\hline \multicolumn{2}{|l|}{ Statin prescribed initially } \\
\hline Atorvastatin (reference) & - \\
\hline Pravastatin & $1.00(0.90-1.11)$ \\
\hline Simvastatin & $1.01(0.91-1.12)$ \\
\hline Lovastatin & $1.09(0.95-1.24)$ \\
\hline Fluvastatin & $1.01(0.80-1.27)$ \\
\hline \multicolumn{2}{|l|}{$\begin{array}{l}\text { Baseline patient characteristics and } \\
\text { comorbidities }\end{array}$} \\
\hline Age† & $1.04(1.04-1.05)$ \\
\hline Male sex & $1.19(1.10-1.28)$ \\
\hline Use of statin before index AMI & $1.26(1.16-1.36)$ \\
\hline Length of hospital stay§ & $1.06(0.98-1.15)$ \\
\hline Time to first statin prescription 9 & $0.70(0.64-0.77)$ \\
\hline Hypertension & $1.01(0.93-1.09)$ \\
\hline Diabetes & $1.60(1.46-1.75)$ \\
\hline Congestive heart failure & $1.51(1.38-1.65)$ \\
\hline Cardiac dysrhythmia & $1.09(0.98-1.20)$ \\
\hline COPD & $1.18(1.06-1.32)$ \\
\hline Cerebrovascular diseases & $1.30(1.12-1.51)$ \\
\hline Chronic renal failure & $1.71(1.49-1.97)$ \\
\hline Malignant disease & $1.97(1.59-2.44)$ \\
\hline Dementia & $1.29(0.93-1.80)$ \\
\hline \multicolumn{2}{|l|}{ In-hospital procedure } \\
\hline Catheterization & $0.76(0.67-0.87)$ \\
\hline $\mathrm{PCl}$ & $0.60(0.48-0.74)$ \\
\hline CABG & $0.33(0.23-0.47)$ \\
\hline \multicolumn{2}{|l|}{$\begin{array}{l}\text { Cardiac medication (before first statin } \\
\text { prescription) }\end{array}$} \\
\hline Nitrate & $1.00(0.92-1.09)$ \\
\hline$\beta$-Blocker & $0.83(0.77-0.90)$ \\
\hline ACE Inhibitor & $1.08(0.99-1.16)$ \\
\hline Antiplatelet agent & $0.88(0.82-0.94)$ \\
\hline Diuretic & $1.46(1.34-1.59)$ \\
\hline Calcium-channel blocker & $1.21(1.12-1.32)$ \\
\hline Warfarin & $1.03(0.92-1.14)$ \\
\hline Digoxin & $1.28(1.16-1.42)$ \\
\hline \multicolumn{2}{|l|}{ Physician and hospital characteristics } \\
\hline Cardiologist & $0.98(0.90-1.07)$ \\
\hline Teaching hospital & $1.08(0.95-1.22)$ \\
\hline Catheterization facility available & $0.98(0.87-1.10)$ \\
\hline Hospital volume** & $0.87(0.41-1.85)$ \\
\hline \multicolumn{2}{|l|}{ Year of index AMI admission } \\
\hline 1997-1998 (reference) & - \\
\hline 1998-1999 & $1.04(0.95-1.15)$ \\
\hline 1999-2000 & $1.06(0.95-1.18)$ \\
\hline 2000-2001 & $1.05(0.92-1.20)$ \\
\hline
\end{tabular}

Note: $\mathrm{Cl}=$ confidence interval.

*Adjusted hazard rates and 95\% Cls for each statin (compared with atorvastatin) were calculated from the data for the 3 provinces and then pooled using a fixed-effects model, with weight being the inverse of the variance of the province-specific estimates.

†Effect of age was linearly related to the outcome, hence "Age" was modelled as a continuous variable.

fAny statin use within 1 year before the index AMI

\$Length of hospital stay was dichotomized at 7 days; $<7$ days was the reference category.

T Time to first statin prescription since discharge was dichotomized at 30 days after discharge;

$<30$ days was the reference category.

**Hospital volume was dichotomized at the third quartile (Q3); Q1-Q3 was the reference category.
Second, unlike patients in RCTs, those in actual practice start statin treatment at different points after discharge and may experience more changes in use over time. Our analysis showed a similar time-to-first statin prescription across the 5 statin groups. This similarity reduced concerns about a potential initial survival advantage associated with a particular statin. In addition, patients were observed to have a high persistence on the statin initially prescribed. To account for switching and stopping treatment, we censored patients at the time they changed exposure status, and the results were unchanged. Nevertheless, the concern would be whether an excess proportion of this switching was related to worsening of clinical status. Our comparison of patients who switched to atorvastatin with those who switched to another statin by rates of hospital readmission and cardiac medication use before switching did not suggest a "channeling over time" due to a change of disease state. ${ }^{46}$

Third, the statins were used at low doses all within the range of starting and maintenance doses recommended in the Compendium of Pharmaceuticals and Specialties. These doses were comparable based on cholesterol-lowering equivalents. ${ }^{21}$ Our adjustment for initial daily dose according to whether it was "at or above target dose" did not affect the results. This adjustment reduced the likelihood of confounding by dose. However, the lack of information on patients' cholesterol levels limited our ability to study the effect of statin dose on cholesterol levels. The observed pattern of prescribing low doses also limited our ability to compare statins at their upper dose limits. The accumulation of new data that reflect possible practice changes of prescribing statins at higher $\operatorname{doses}^{28}$ will help to answer this question.

Fourth, our follow-up period was shorter than that in large-scale RCTs of statin therapy. However, the RCTs would have required a longer follow-up to see an effect because they enrolled only stable patients 3-6 months after AMI. Our study patients were included immediately after their discharge from hospital and thus were at higher risk of recurrent AMI or death. Early initiation of statin therapy after AMI has been found to be beneficial. ${ }^{47}$ The PROVE IT-TIMI 22 trial, which enrolled patients within 10 days after experiencing an acute coronary syndrome and randomly assigned them to receive either standard or intensive statin therapy, observed a difference between the 2 treatment arms after 6 months and at the end of the trial (follow-up 1.5 to 3 years, mean 2 years). ${ }^{28}$ Accordingly, our median follow-up of 2.3 years and maximum of 5 years is of reasonable length to detect possible differences in outcomes.

Fifth, because we studied all-cause mortality in an elderly cohort followed for several years, death from other causes may have been an issue. However, most of the deaths in the study population occurred relatively soon after the index AMI, and therefore we more than likely captured cardiac-related deaths. Also, we adjusted for major 
morbid conditions in elderly patients, including dementia, malignant disease, congestive heart failure and chronic renal failure.

Sixth, we used prescription claims as a proxy for actual statin use. However, given that the data represented filled prescriptions instead of written prescriptions, and that the patients refilled their prescriptions regularly, it was likely that the patients were compliant.

Finally, although the conclusion toward the effect of lovastatin and fluvastatin should be more conservative because of the relatively low number of patients prescribed these agents, the point estimates of the relative effects between statins were all in the neighborhood of 1.0, and the accompanying $95 \%$ CIs were narrow. If we consider a range of $10 \%-20 \%$ relative difference in hazard ratios as the region of clinical equivalence, we have good evidence to declare equivalence among these statins.

In conclusion, our study provides evidence that, under current usage, statins are equally effective for the secondary prevention of AMI in elderly patients.

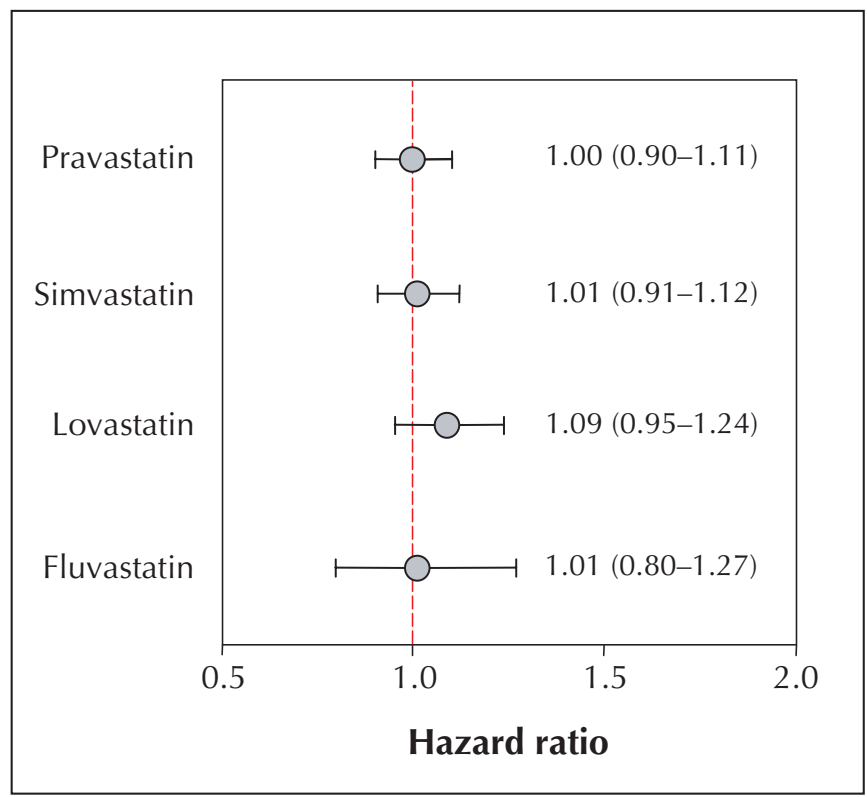

Fig. 1: Pooled adjusted hazard ratios and $95 \%$ confidence intervals (error bars) for the combined outcome of recurrent acute myocardial infarction (AMI) or death from any cause among elderly patients prescribed statin therapy after an AMI. Atorvastatin is the reference drug. Hazard ratios were adjusted for age, sex, statin use before the index AMI, hypertension, diabetes mellitus, congestive heart failure, chronic obstructive pulmonary disease, cerebrovascular disease, chronic renal failure, dementia, malignant disease, in-hospital procedures (catheterization, percutaneous coronary intervention, coronary artery bypass graft surgery), cardiac medications ( $\beta$-blockers, angiotensinconverting-enzyme inhibitors, nitrates, antiplatelet agents, calcium-channel blockers, diuretics, warfarin, digoxin, fibrates), specialty of treating physician, hospital type, length of hospital stay, time to first prescription and year of index AMI.
This article has been peer reviewed.

From the Department of Epidemiology and Biostatistics, McGill University, and the Division of Clinical Epidemiology, Montreal General Hospital, Montréal, Que. (Zhou, Rahme, Abrahamowicz, Pilote); the Institute for Clinical Evaluative Science, Toronto, Ont. (Tu, Austin); the Division of Cardiology, University of British Columbia, and the Centre for Health Evaluation and Outcome Sciences, Vancouver, BC (Humphries); and the Sir Mortimer B. Davis Jewish General Hospital, Montréal, Que. (Eisenberg)

Competing interests: None declared.

Contributors: Zheng Zhou prepared the manuscript and, with Louise Pilote and Elham Rahme, was responsible for the study design and the analysis and interpretation of the data. Louise Pilote, Elham Rahme, Jack Tu, Karin Humphries, Michal Abrahamowicz, Mark Eisenberg and Peter Austin participated in the development of the study concept, the acquisition of data (Ontario data: Tu and Austin; Quebec data: Pilote, Rahme, Abrahamowicz and Eisenberg; BC data: Humphries) and critical revision of the manuscript for important intellectual content. Peter Austin contributed to the analysis of Ontario data. All of the authors approved the final version of the manuscript for publication.

Acknowledgements: This study was funded in part by a grant from the Canadian Institute for Health Research (CIHR, grant no. MOP-53181). The work in Ontario was additionally supported by a CIHR grant (no. MOP-14671). Zheng Zhou was supported by a scholarship from the Natural Science and Engineering Research Council of Canada and a fellowship from the Canadian Cardiovascular Outcome Research Team. Elham Rahme is a Research Scholar funded by the Arthritis Society. Michal Abrahamowicz is a James McGill Professor at McGill University. Jack Tu is the Research Chair in Health Services Research of the CIHR. Mark Eisenberg is a clinician scientist funded by Fonds de la recherche en Santé du Québec. Karin Humphries is a Scholar of the Michael Smith Foundation. Peter Austin is supported in part by a CIHR New Investigator Award. Louise Pilote is a CIHR Research Scholar.

\section{References}

1. Randomised trial of cholesterol lowering in 4444 patients with coronary heart disease: the Scandinavian Simvastatin Survival Study (4S). Lancet 1994;344 (8934): 1383-9.

2. Sacks FM, Pfeffer MA, Moye LA, Rouleau JL, Rutherford JD, Cole TG, et al. The effect of pravastatin on coronary events after myocardial infarction in patients with average cholesterol levels. Cholesterol and Recurrent Events Trial Investigators. N Engl F Med 1996;335(14):1001-9.

3. Miettinen TA, Pyorala K, Olsson AG, Musliner TA, Cook TJ, Faergeman O, et al. Cholesterol-lowering therapy in women and elderly patients with myocardial infarction or angina pectoris: findings from the Scandinavian Simvastatin Survival Study (4S). Circulation 1997;96(12):4211-8.

4. Lewis SJ, Sacks FM, Mitchell JS, East C, Glasser S, Kell S, et al. Effect of pravastatin on cardiovascular events in women after myocardial infarction: the cholesterol and recurrent events (CARE) trial. 7 Am Coll Cardiol 1998;32(1):140-6.

5. Prevention of cardiovascular events and death with pravastatin in patients with coronary heart disease and a broad range of initial cholesterol levels. The Long-Term Intervention with Pravastatin in Ischaemic Disease (LIPID) Study Group. N Engl 7 Med 1998;339(19):1349-57.

6. Sacks FM, Moye LA, Davis BR, Cole TG, Rouleau JL, Nash DT, et al. Relationship between plasma LDL concentrations during treatment with pravastatin and recurrent coronary events in the Cholesterol and Recurrent Events trial. Circulation 1998;97(15):1446-52.

7. Schwartz GG, Olsson AG, Ezekowitz MD, Ganz P, Oliver MF, Waters D, et al; Myocardial Ischemia Reduction with Aggressive Cholesterol Lowering (MIRACL) Study Investigators. Effects of atorvastatin on early recurrent ischemic events in acute coronary syndromes: the MIRACL study: a randomized controlled trial. FAMA 2001;285(13):1711-8.

8. Athyros VG, Papageorgiou AA, Mercouris BR, Athyran W, Symconidis AN, Basayannis EO, et al. Treatment with atorvastatin to the National Cholesterol Educational Program goal versus "usual" care in secondary coronary heart disease prevention. The GREek Atorvastatin and Coronary-heartdisease Evaluation (GREACE) study. Curr Med Res Opin 2002;18(4):220-8.

9. Mamdani MM, Tu JV. Did the major clinical trials of statins affect prescribing behaviour? CMA7 2001;164(12):1695-6.

10. Jackevicius CA, Anderson GM, Leiter L, Tu JV. Use of the statins in patients after acute myocardial infarction: does evidence change practice? Arch Intern Med 2001;161(2):183-8.

11. Baxter C, Jones R, Corr L. Time trend analysis and variations in prescribing lipid lowering drugs in general practice. BMf 1998;317:1134-5.

12. Lemaitre RN, Furberg CD, Newman AB, Hulley SB, Gordon DJ, Gottdiener $\mathrm{JS}$, et al. Time trends in the use of cholesterol-lowering agents in older adults. Arch Intern Med 1998;158:1761-8.

13. Furberg CD, Herrington DM, Psaty BM. Are drugs within a class interchangeable? Lancet 1999;354(9185):1202-4. 
14. Furberg CD. Class effects and evidence-based medicine. Clin Cardiol 2000;23 (7 Suppl 4):IV15-9.

15. Kennedy HL, Rosenson RS. Physicians interpretation of class effects: A need for thoughtful re-evaluation. 7 Am Coll Cardiology 2002;40(1):19-26.

16. Knopp RH. Drug Treatment of Lipid Disorders. N Engl f Med 1999;341(7): 498-511.

17. Bakker-Arkema RG, Davidson MH, Goldstein RJ. Efficacy and safety of a new HMG-CoA reductase inhibitor, atorvastatin, in patients with hypertriglyceridemia. 7AMA 1996;275:128-33.

18. Vaughan CJ, Murphy MB, Buckley BM. Statins do more than just lower cholesterol. Lancet 1996;348:1079-82.

19. Hsu I, Spinler SA, Johnson NE. Comparative evaluation of the safety and efficacy of HMG-CoA reductase inhibitor monotherapy in the treatment of primary hypercholesterolemia. Ann Pharmacother 1995;29:743-59.

20. Jackevicius CA, Tu K, Filate WA, Brien SE, Tu JV. Trends in cardiovascular drug utilization and drug expenditures in Canada between 1996 and 2001 Can 7 Cardiol 2003;19(12):1359-66.

21. Jones P, Kafonek S, Laurora I, Hunninghake D. Comparative dose efficacy study of atorvastatin versus simvastatin, pravastatin, lovastatin, and fluvastatin in patients with hypercholesterolemia (the CURVES study). Am 7 Cardiol 1998;81:582-7.

22. Farnier M, Portal JJ, Maigret P. Efficacy of atorvastatin compared with simvastatin in patients with hypercholesterolemia. 7 Cardiovasc Pharmacol Ther 2000;5(1):27-32

23. McKenney JM, Jones PH, Adamczyk MA, Cain VA, Bryzinski BS, Blasetto JW. Comparison of the efficacy of rosuvastatin versus atorvastatin, simvastatin, and pravastatin in achieving lipid goals: results from the STELLAR trial. Curr Med Res Opin 2003;19(8):689-98.

24. Joukhadar C, Klein N, Prinz M, Schrolnberger C, Vukovich T, Wolzt M, et al. Similar effects of atorvastatin, simvastatin and pravastatin on thrombogenic and inflammatory parameters in patients with hypercholesterolemia. Thromb Haemost 2001;85(1):47-51.

25. Wiklund O, Mattsson-Hulten L, Hurt-Camejo E, Oscarsson J. Effects of simvastatin and atorvastatin on inflammation markers in plasma. F Intern Med 2002;251(4):338-47.

26. Seljeflot I, Tonstad S, Hjermann I, Arnesen H. Reduced expression of endothelial cell markers after 1 year treatment with simvastatin and atorvastatin in patients with coronary heart disease. Atherosclerosis 2002;162(1):179-85.

27. Nissen SE, Tuzcu EM, Schoenhagen P, Brown BG, Ganz P, Vogel RA, et al. Effect of intensive compared with moderate lipid-lowering therapy on progression of coronary atherosclerosis: a randomized controlled trial. $7 A M A$ 2004;291(9):1071-80.

28. Cannon CP, Braunwald E, McCabe CH, Rader DJ, Rouleau JL, Belder R, et al; Pravastatin or Atorvastatin Evaluation and Infection Therapy-Thrombolysis in Myocardial Infarction 22 Investigators. Intensive versus moderate lipid lowering with statins after acute coronary syndromes. NEngl F Med 2004;350(15):1495-504.

29. LaRosa JC. New and emerging data from clinical trials of statins. Curr Atheroscler Rep 2004;6(1):12-9.

30. Kennedy CC, Brien SE, Tu JV. An overview of the methods and data in the CCORT Canadian Cardiovascular Atlas project. Can 7 Cardiol 2003;19:655-63.

31. Tu JV, Austin PC, Filate WA, Johansen H, Brien S, Pilote L. Outcomes of acute myocardial infarction in Canada. Can 7 Cardiol 2003;19:893-901.

32. Levy AR, Tamblyn RM, Fitchett D, McLeod PJ, Hanley JA. Coding accuracy of hospital discharge data for elderly survivors of myocardial infarction. Can 7 Cardiol 1999;15(11):1277-82.

33. Humphries KH, Rankin JM, Carere RG, Buller CE, Kiely FM, Spinelli JJ. Comorbidity data in outcomes research: are clinical data derived from administrative databases a reliable alternative to chart review? 7 Clin Epidemiol 2000;53(4):343-9.

34. International classification of diseases, 9th revision (clinical modification). Washington: Public Health Service, US Department of Health and Human Services; 1998

35. Tu JV, Naylor CD, Austin P. Temporal changes in the outcomes of acute myocardial infarction in Ontario, 1992-1996. CMA7 1999;161(10):1257-61.

36. Law MR, Wald NJ, Rudnicka AR. Quantifying effect of statins on low density lipoprotein cholesterol, ischaemic heart disease, and stroke: systematic review and meta-analysis. BMF 2003;326(7404):1423.

37. Sever PS, Dahlof B, Poulter NR, Wedel H, Beevers G, Caulfield M, et al. Prevention of coronary and stroke events with atorvastatin in hypertensive patients who have average or lower-than-average cholesterol concentrations, in the Anglo-Scandinavian Cardiac Outcomes Trial-Lipid Lowering Arm (ASCOT-LLA): a multicentre randomised controlled trial. Lancet 2003;361(9364):1149-58.

38. Heart Protection Study Collaborative Group. MRC/BHF Heart Protection Study of cholesterol lowering with simvastatin in 20,536 high-risk individuals: a randomised placebo-controlled trial. Lancet 2002;360:7-22.

39. Downs JR, Clearfield M, Weis S, Whitney E, Shapiro DR, Beere PA, et al. Primary prevention of acute coronary events with lovastatin in men and women with average cholesterol levels: results of AFCAPS/TexCAPS. Air Force/Texas Coronary Atherosclerosis Prevention Study. FAMA 1998;279(20):1615-22.
40. Serruys PW, Feyter P, Macaya C, Kokott N, Puel J, Vrolix M, et al; Lescol Intervention Prevention Study (LIPS) Investigators. Fluvastatin for prevention of cardiac events following successful first percutaneous coronary intervention. A randomized controlled trial. FAMA 2002;287(24):3215-22.

41. Deeks JJ, Altman DG, Bradburn MJ. Statistical methods for examining heterogeneity and combining results from several studies in meta-analysis. In: Egger M, Smith GD, Altman DG, editors. Systematic reviews in bealth care: metaanalysis in context. 2nd ed. London: BMJ Publishing Group; 2001. p. 285-312.

42. Armitage P, Berry G, Matthews JNS. Comparison of several groups. Statistical methods in medical research. 4th ed. Oxford (UK): Blackwell Science Ltd.; 2002. p. 208-35

43. Sin DD, Tu JV. Inhaled corticosteroids and the risk of mortality and readmission in elderly patients with chronic obstructive pulmonary disease. Am 7 Respir Crit Care Med 2001;164(4):580-4.

44. Shepherd J, Blauw GJ, Murphy MB, Bollen EL, Buckley BM, Cobbe SM, et al; PROSPER study group. PROspective Study of Pravastatin in the Elderly at Risk. Pravastatin in elderly individuals at risk of vascular disease (PROSPER): a randomised controlled trial. Lancet 2002;360(9346):1623-30.

45. Salas M, Hofman A, Stricker BH. Confounding by indication: an example of variation in the use of epidemiologic terminology. Am 7 Epidemiol 1999;149 (11):981-3.

46. Blais L, Ernst P, Suissa S. Confounding by indication and channeling over time: the risks of beta2-agonists. Am 7 Epidemiol 1996;144(12):1161-9.

47. Olsson AG, Schwartz GG. Early initiation of treatment with statins in acute coronary syndromes [review]. Ann Med 2002;34(1):37-41.

Correspondence to: Dr. Louise Pilote, Division of Clinical Epidemiology, Rm. L10-421, Montreal General Hospital, 1650 Cedar Ave., Montréal QC H3G 1A4; fax 514 934-8293. louise.pilote@mcgill.ca

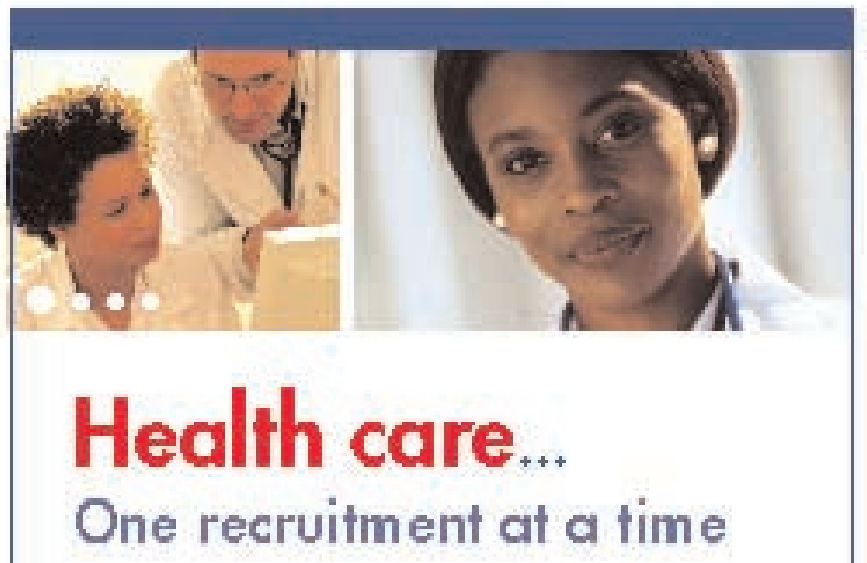

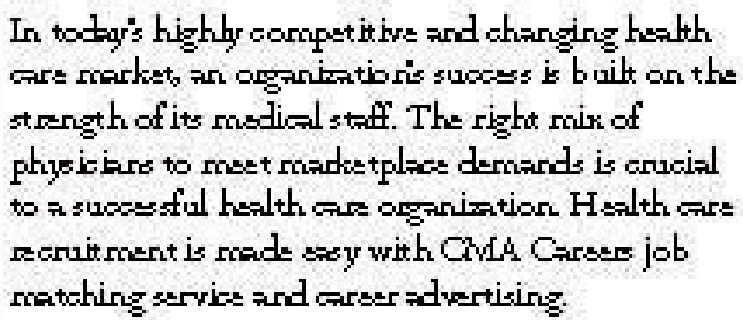

Find your mix ... visit coreers af ethated hoday! 